\title{
برنامج تثقيفي للإسعافات الأولية للفرق الرياضية بمحافظة اسوان
}

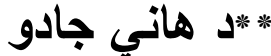

" اسراءعزت علي محمد هائ جاءو

\section{مقدمة ومشكلة البحث :}

يعتبر علم الإصـابات بصفة عامـة والإسعافات الأولية بصفة خاصـة أحد أهم

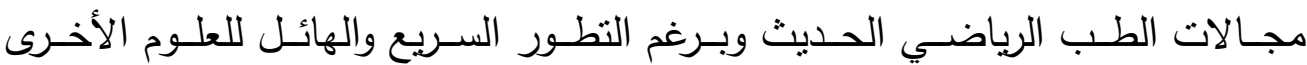

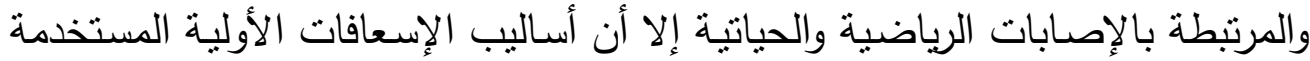
أثثاء الأزمات والحوادث والكوارث والاختبارات المستخدمة أثناء ذلك لم تقنن حتى الآن عند أفراد المجتمع بصفة عامة والفرق الرياضية بصفة خاصة.

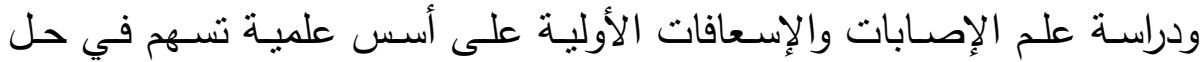
العديد من المشكلات والأزمات المختلفة بالمجال الرياضي وإسعاف المصـابين بشكل

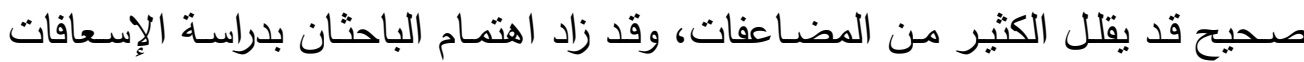

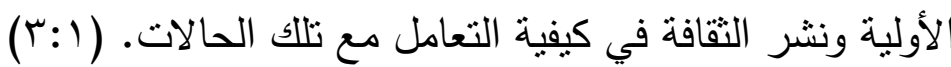
وقد توصل كل من "باشـكيروف (1911) و ونيلزينـا" (.91 1) بعد عديد من سنوات الدراسة والبحث إلي أن كثير من الإصابات يمكن توقعها والحد من مضاعفاتها بـاتهن عند حدوثها وبالتالي التحذير والوقاية منها وذلك عند تحديد الأسباب الرئيسية المؤدية

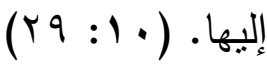

كمـا نلاحظ انـه تزداد نسبة الإصـابات لدي القائمين باسـوان وفق بيـان هيئة

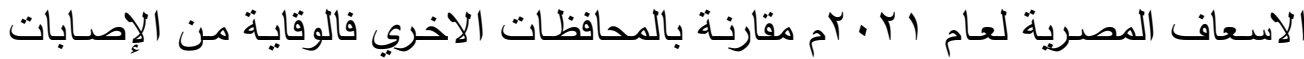

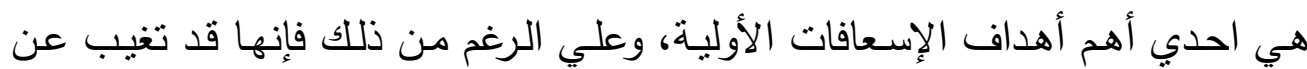

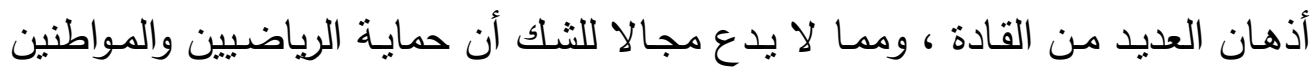

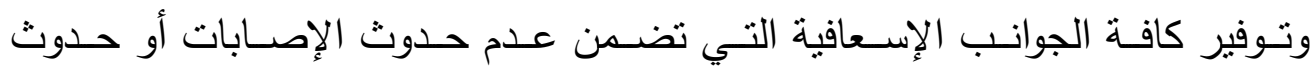

* مدرس بقسم العلوم الصحة الرياضية، كلية التربية الرياضية باسوان، جامعة أسوان "باحثة بالماجستير بكلية التربية الرياضية - جامعة اسوان 
المضاعفات أو وقوع الضرر عليه من الأمور الرئيسية التي لا يجب أن تخلو العملية

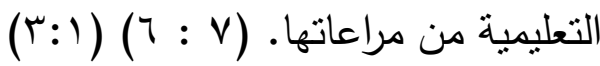

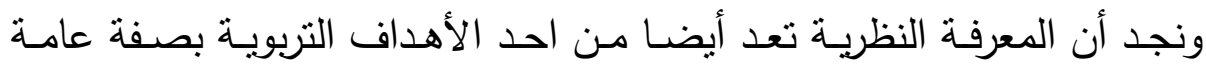

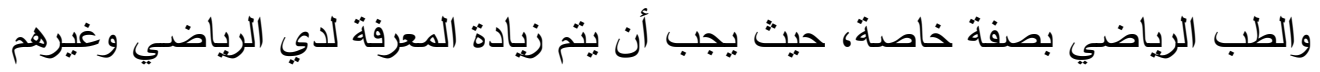

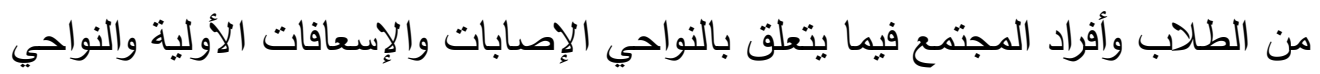

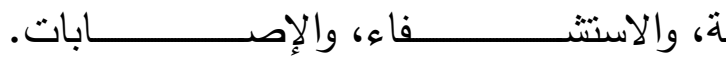

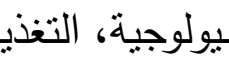
الفست

$$
(9: \wedge)(\vee: \vee)
$$

فيـري "وليـامز Williams" أن المجـال المعرفي هـو" المجموعـة الأوليـة مـن الصفات أو السمات التي نؤصل المعرفة وتعمقها، والتي تأخذ شكل المهارات المتعددة الأبعـاد المعتمدة علي التفكير من اجل استظهار واسترجاع ومعالجـة مدركات الفرد

$$
\text { للمعلومات". (19 (19V ) }
$$

ويعرف سنجر، ديك Singer \& dick المجال المعرفي للتربية بأنه: "ذلك المجال الذي يشتنمل علي المهارات والقدرات العقلية للتناميذ كالمعارف وقابليتها للشرح،

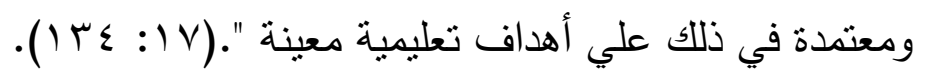
ويري "أمين أنور الخولي" أن المعرفة تهدف إلي التعرف علي العلاقة بين أي

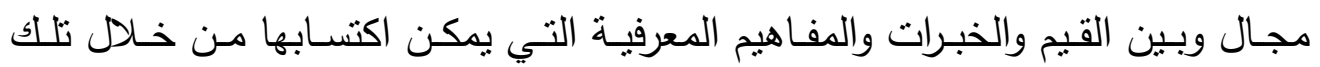
المجال أو الدراسة الخاصة بموضوع بذاته كما تهدف إلي تتمية المعلومات و المهارات المعرفية كالفهم والتطبيق والتحليل و التركيب والتقويم لجوانب معرفية في جوهرها رغم بـان

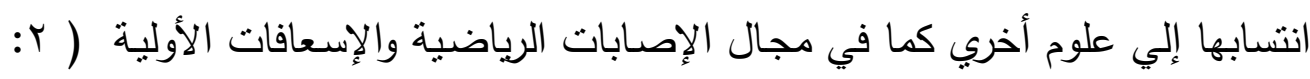
. (₹0:r) (109

ويؤكد "جيمس اوليفر j.oliver" ان هناك علاقة وثيقة بين الأنشطة البدنية

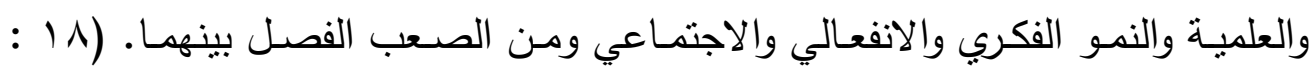

كما يري "تثارلز Charles" أن تتمية المهارات العقلية لا تقل أهمية عن تتمية المهارات التطبيقيـة والبدنيـة والعمليـة إلا أن هنـاك بعض التهيه المدربين يهملـون المهارات 
العقلية لكونها غبر ملموسة بشكل مادي وهناك فارق بين التفكير أثناء الأزمة والتفكير في سرعة اتخاذ القرار أثتاء حدوث الأزمات والحوادث والكوارث الطبيعية والرياضية.

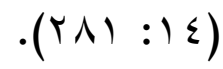

وبالرغم من معرفة ومتابعة كثير من أفراد المجتمع للمعلومات المتعلقة بمجال

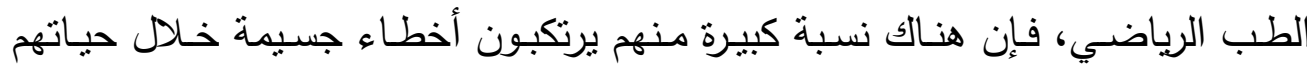
وبالبحث والدراسة وجد أن هذا يرجع إلي انتشار كثير من المفاهيم الخاطئة والمتداولة في مجال الطب الرياضـي بصفة عامـة ومجال الإسعافات الأولية بصفة خاصـة.(ه :

فلابد أن يقوم تكوين العادات الصحية في حياة الإنسان بصفة عامـة علي فهم وإدراك عقلي تام، مهما كان مستوي هذا الإدراك من الناحية العملية، فالطفل الصغير لهاه تبسط له الحقائق الصحية حتى يفهمها ويعرفها بعناية،.

\section{(7: $:$ )}

كما تشكل اعتبارات ومفاهيم الأمسان والسـلامة للإصـابات الثـائعة والإسـعافات

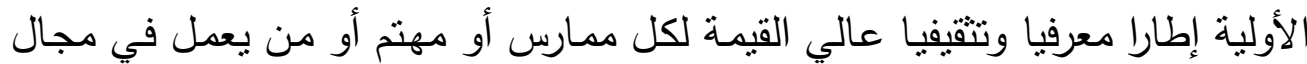
الرياضـة، لأنها تعد ثقافة وقائية من هذه الإصـابات أولا ثم هي ثقافة علافية علاجية تأهيلية

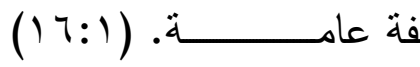
لـال الإصـ

\section{$($ ) $r O: Y)$}

ويري "علي محمد جلال الدين، محمد قدري بكري" (11 + إ) أن التربية البدنية

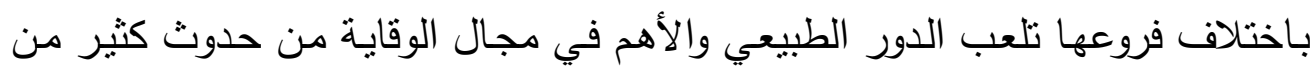
الإصابات والأمراض. (v: (0)

كما أكد العديد من العلماء علي أن الاختبارات المعرفية غالبا ما تستخدم بجانب

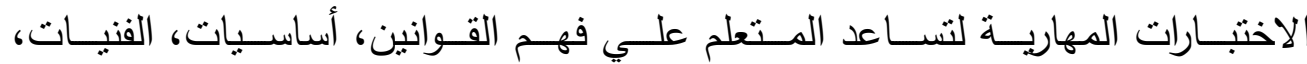
المصطلحات، في المجـال المسـتهدف لمـا لها أهميتهـا في تحقيـق أهداف البرنـامج

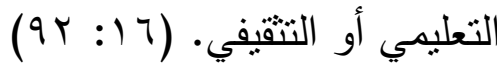


حيـث أن التقبـيم في عمليـة التثقـف لا يكتمـل دون أن يسـتخدم الاختبـارات

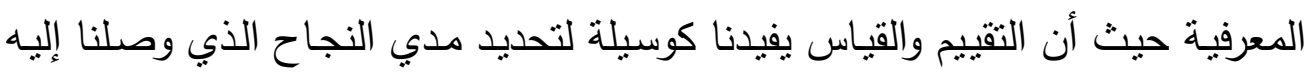

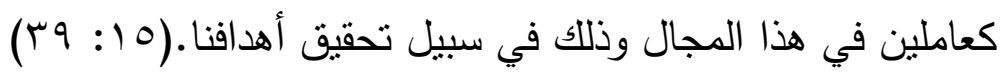

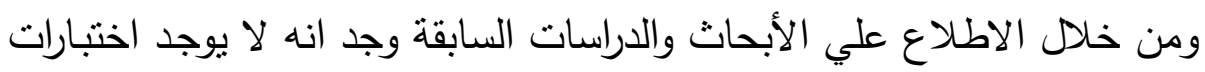

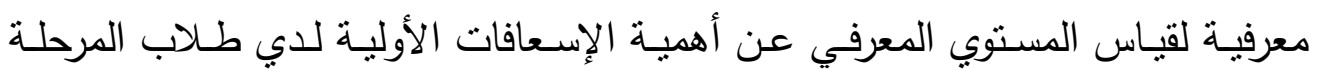

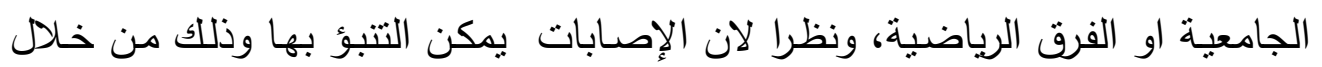

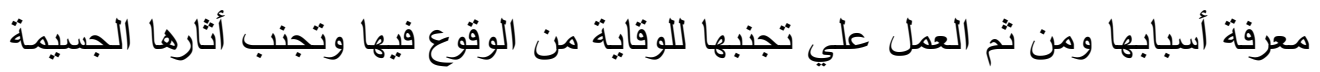

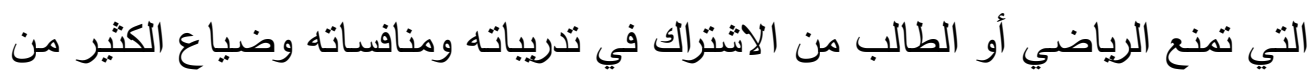

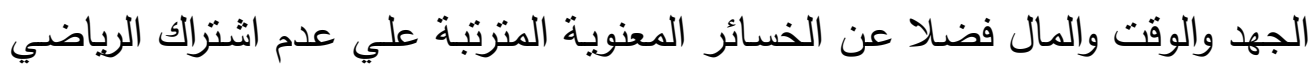
في البطولات الهامة نتيجة الإصابة وضياع فرص حصد الميداليات ورفع الأعلام عالية في البطولات والمحافل الدولية.

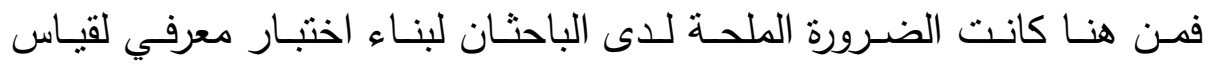

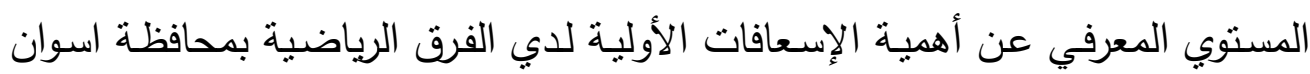

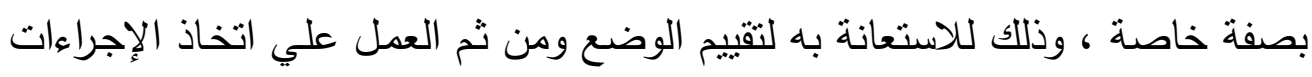

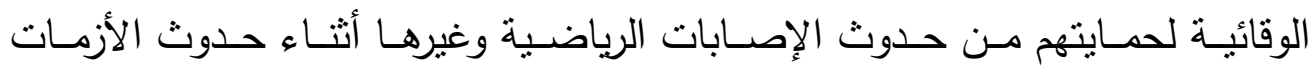
والكوارث والحد مـن حدوث المضـاعفات لـدى المصـابين وتقديم المسـاعدات بجـوار المتخصصين من الأطباء والعاملين بهيئة الإسعاف المصرية. هدف البحث : - يهدف البحث إلي تصميم برنامج تثقيفي عن أهمية الإسعافات الأولية لدي الفرق الرياضية بمحافظة اسوان. r- التعرف على تأثثر البرنامج التقيفي على العينة قيد البحث من خـال الاختبار المعرفي المصمم من قبل الباحثان وتطبيقه قبل وبعد البرنامج.

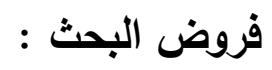
1- توجد فروق دالة إحصائيا بين القياس القبلي والقياس البعدي في المستوي المعرفي لدي العينة قيد البحث لصالح القياس البعدي بعد تطبيق البرنامج التثقيفي. 
r- هـل بمكن بنـاء اختبـار معرفي لقيـاس المستوي المعرفي لدي الفـرق الرياضية بمحافظة اسوان عن أهمية الإسعافات الأولية. مصطلحات البحث:

- الإصابة الرياضية Sport Injury -

هي إعطاب قد تصيب الجهاز الساند المحرك (عضلات- عظام- مفاصلالأعصاب) فتعوق معها التطور الديناميكي لمستوى الرياضي وتحول دون استمراره في

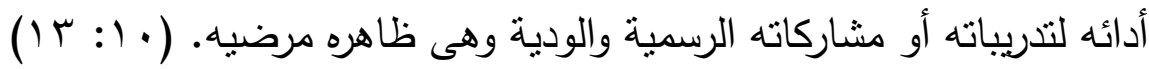

- المقصود بالخدمات الطبية العاجلة:

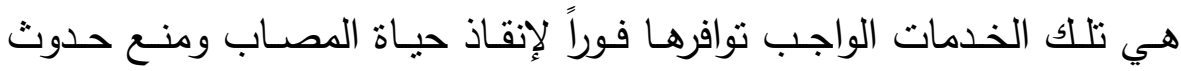
مضاعفات أو إعاقة له، وعند حدوث الإصابة يمر المصاب بالمراحل التالية:

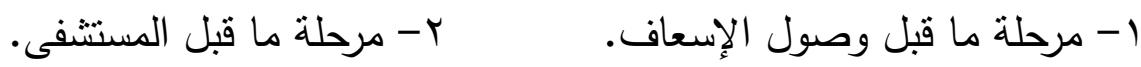

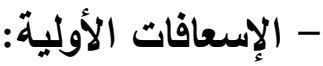
هي الرعاية الفورية والمؤقتة التي تقدم للمصاب قبل الوصول إلى المستشفى أو وصول الطبيب.(1:(1) - الثقافة Culture:

هي ذلك الكل المركب الذي يتضمن المعرفة، العقيدة، الفن، الأخلاق، القانون، العادة، وأية قدرات أخري، والطباع التي يكتسبها الفرد كعضو في المجتمع. (r إ: ب) - التثقيف Education:

يعني تقديم المعلومات والبيانات والحقائق العلمية النظرية والتطبيقية التي ترتبط

$$
\text { الدراسات المرتبطة: الإسعافات الأولية. (تعريف إجرائي) }
$$

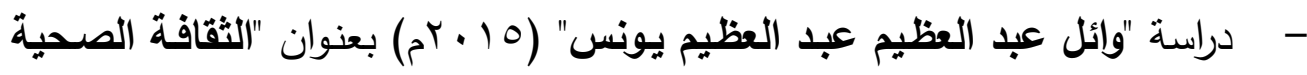

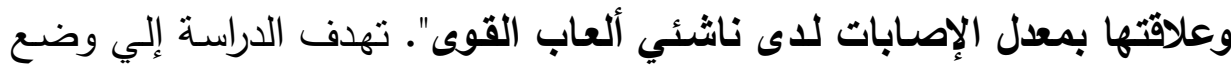

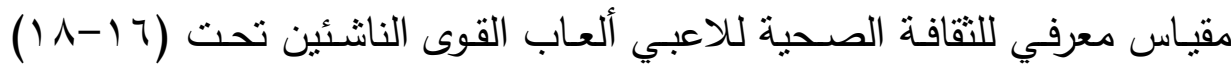

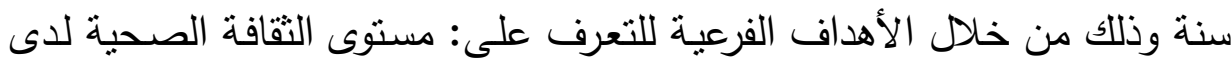

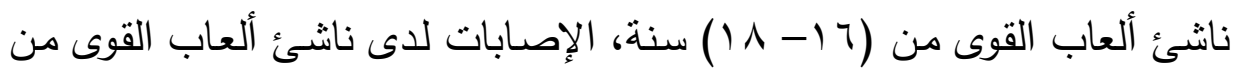




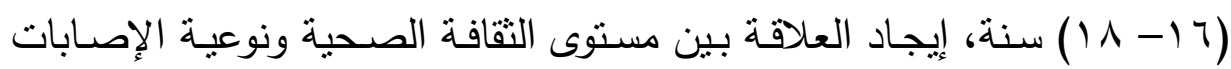

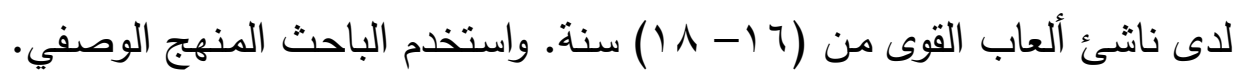

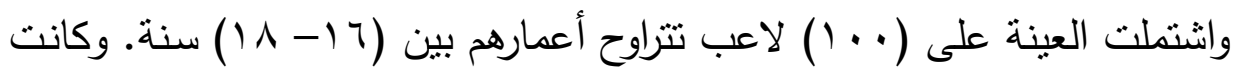

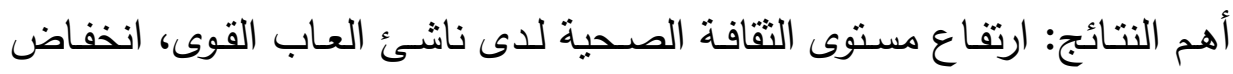

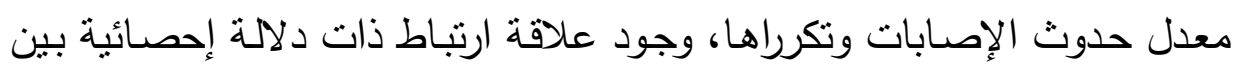

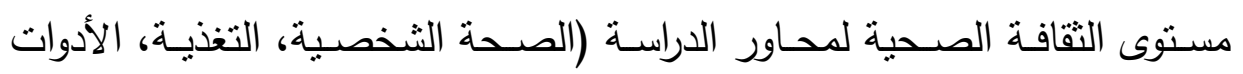

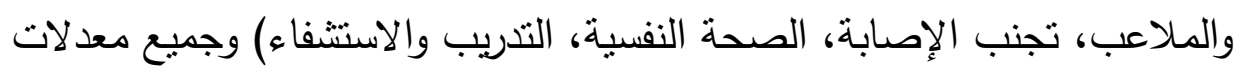
حدوث الإصابات لدى ناشئ العاب القوى.(r ( )

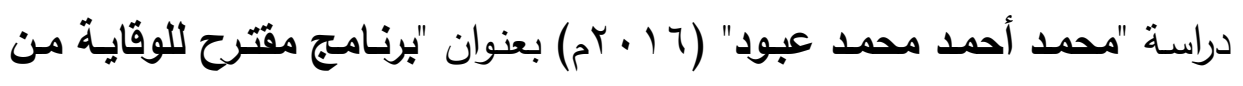

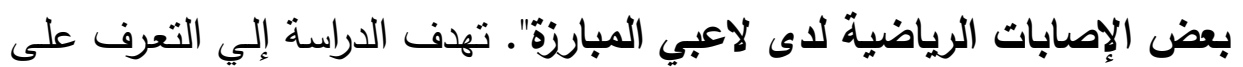

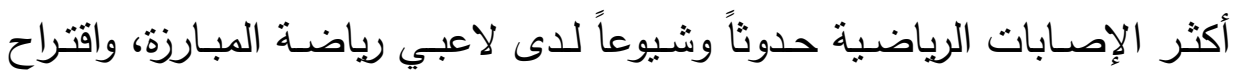

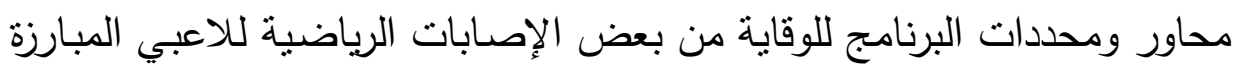

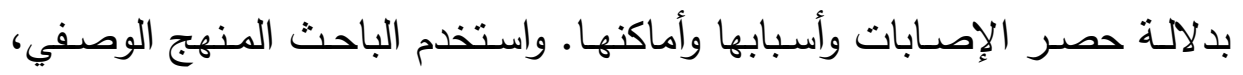

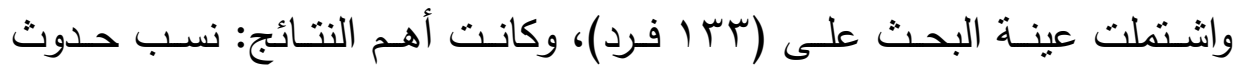

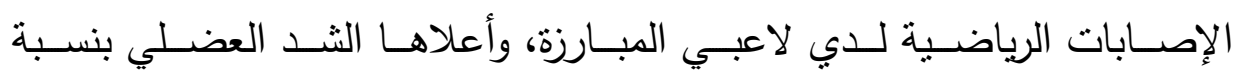

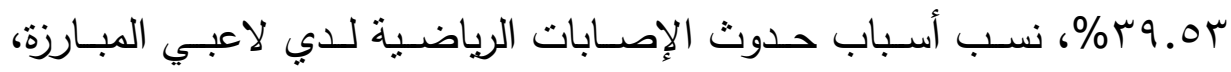

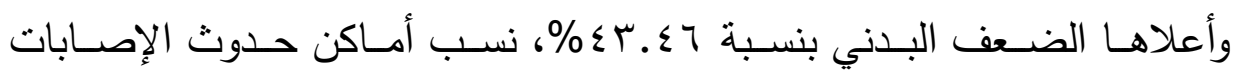

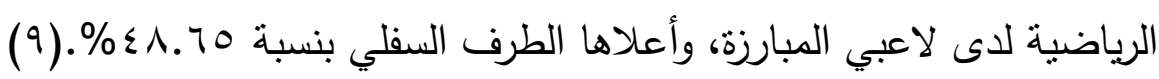
الاراسات الأجنبية:

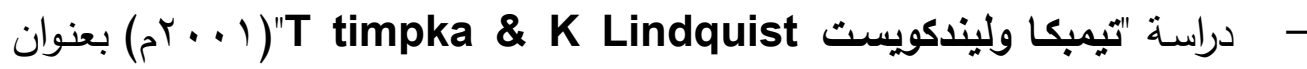
"الوقاية من الإصـابات أثناء النشاط البدني وفقا لإجراءات منظمة الصحة للأهن

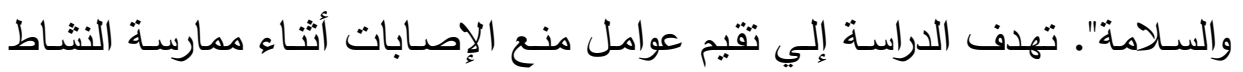
البدني وفقا لأجراء منظمة الصحة العالمية للأمن والسـامة وأجريت هذه الأديات الدراسة

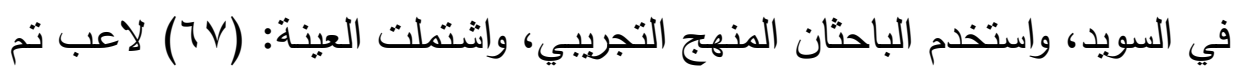

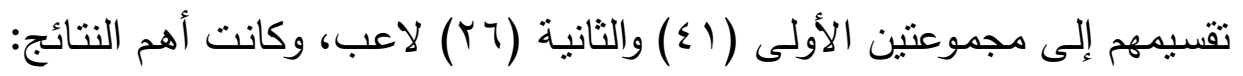

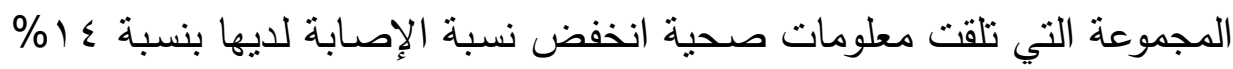

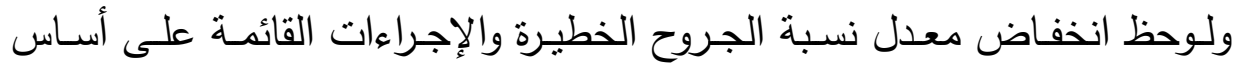


برنامج للوقايـة والبرامج التعليمية التي يمكن أن تقلل من عبأ الإصـابات المتعلقة

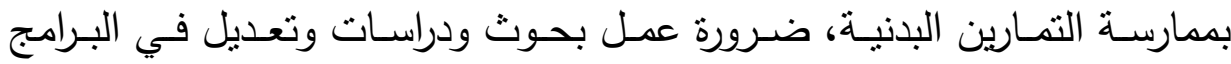

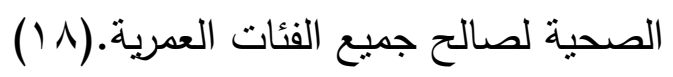

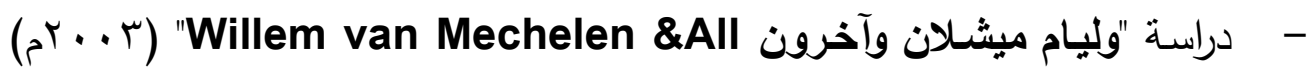
بعنوان "الوقاية من الإصابة باستخدام الإحماء وتدريبات الإطالة". تهدف الدراسة

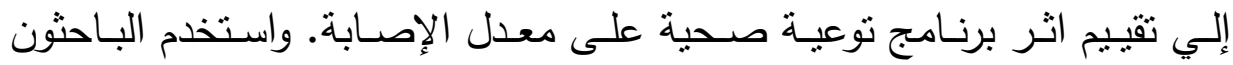

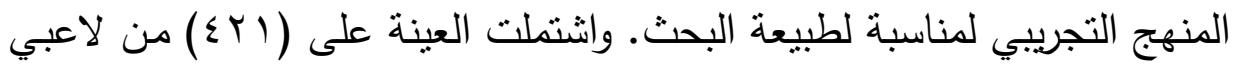
العدو تم تقسيمه إلى مجموعتين خضعت المجموعة الأولى لبرنامج نوعية صحية

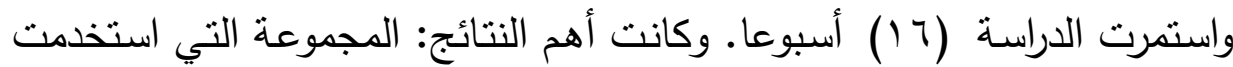
برنامج التوعية الصحية تأثرت ايجابيا وانخفض معدل الإصابة بها عن المجموعة وانة

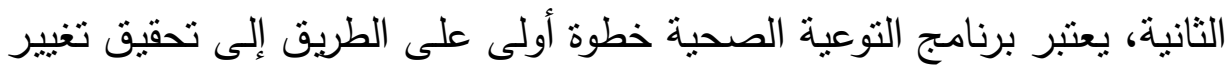

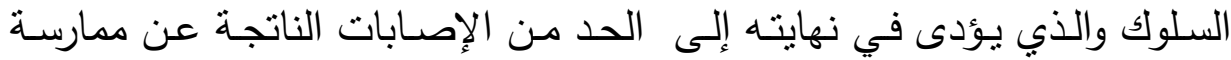

$$
\begin{aligned}
& \text { الرياضة. (9 (1) } \\
& \text { إجراءات البحث : } \\
& \text { منهج البحث : }
\end{aligned}
$$

اسـتخدم الباحـث المـنهج التجريبـي بأسـلوب القبـاس القبلـي والقيـاس البعـدي

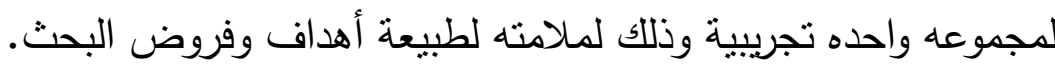

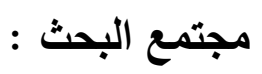
الفرق الرياضية بمحافظة اسوان. عينة البحث : ع تم اختيـار عينـة البحث بالطريقـة العمديـة مـن مجموعـة مـن الفـرق الرياضـية

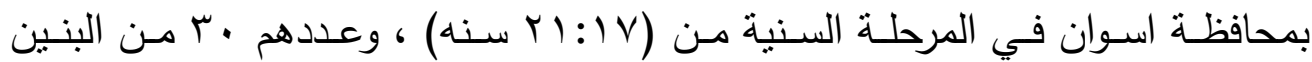
للارراسة الاستطلاعية و .0 طالب للعينة الأساسية للبحث.

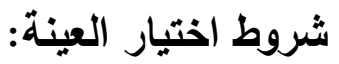

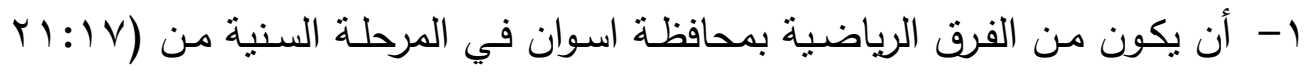
سنه). 
r- أن يكون لديهم الرغبة في التطوع لإجراء التجربة.

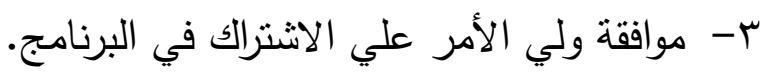

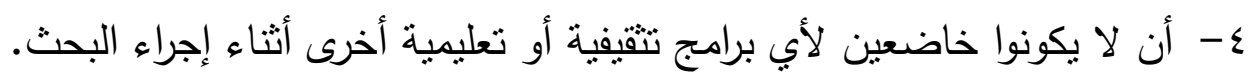
0- الانتظام والاستمرار في البرنامج المقترح طوال فترة إجراء التجربة.

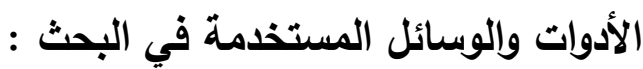
- - استمارة استطلاع رأي الخبراء في محاور الاختبار المعرفي المقترح. - - - استمارة استطلاع رأي الخبراء في محتوي وعبارات الاختبار المعرفي. - - الاختبار المعرفي الذي تم بناءه لقياس المستوي المعرفي بعد موافقة الخبراء عليه. - - استمارة استطلاع رأي الخبراء في البرنامج التقبفي المقترح من قبل الباحث للعينة قيد البحث. الأجهزة والأدوات المستخدمة في تتفيذ البرنامـج التثقيفي: - - قاعة محاضرات لتتفيذ محتوي البرنامج التثقيفي المقترح.

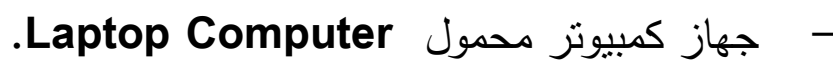
-

التثقيفي باستخدام برنامج العرض التقديمي للشرائح عowerPoint. متغيرات البحث: - n كي يتم التوصل إلى نتائج دقيقة في هذه الدراسـة قام الباحثنان بمحاولة ضبط المتغير المستقل (البرنامج التنقيفي المقترح) الذي قد يؤثر على المتغير التابع (المستوي (المعرفي).

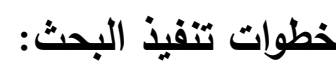
إعداد البرنامج التثقيفي المقترح: تم عمـل مسـح للمراجـع العلميـة والدراسـات السـابقة ومواقـع شـبكة المعلومـات الدولية، وبناء عليه تم تحديد المحاور الرئيسية للبرنامج التثقيفي المقترح ومحتوي كل محور لعرضه علي الخبراء.

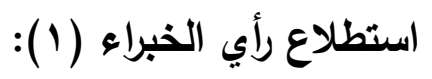


تم إعداد استمارة استطلاع رأي الخبراء (مرفق ب) التي تحتوي على المحاور الرئيسية للبرنامج التنقيفي المقترح، وكذلك موضوعات المحتوي النظري لكل محور من محاور البرنامج في نقاط وذلك بهدف التعرف على أراء الخبراء فيما يتعلق بكل من: - مناسبة المحاور المقترحة للبرنامج التنقيفي المقترح. - اقتراح تعديل لأي محور من محاور البرنامج التقيفي المقترح. - إضافة محاور أخري للبرنامج التثقيفي المقترح.

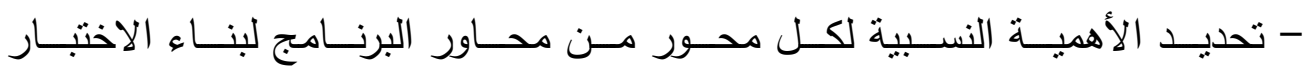
المعرفي.

- مدي مناسبة المحتوي النظري لكل محور من محاور البرنامج.

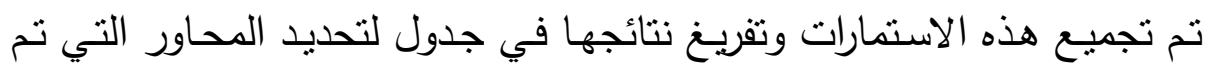

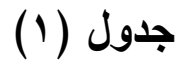

قبولها وتحديد الأهمية النسبية لكل محور •

محاور البرناميج التثقيفي المقترح والأهمية النسبية لكل محور

\begin{tabular}{|c|c|c|c|}
\hline اللالهمبية & علي المحبرو المقتراء المقين & المحور & r \\
\hline$\% 9$ & 9 & مقدمة عن الخدمات الطبية العاجلة & 1 \\
\hline$\% 9$ & 9 & الإسعافات الأولية & $r$ \\
\hline$\% 1$. & 1. & المهارات الأساسية لأخصائي الإسيأية ومسافات & $\mu$ \\
\hline$\% 1$. & 1 . & التقييم المبدئي للمصاب & $\varepsilon$ \\
\hline$\% 1$. & 1. & الرعاية الأولية للمرضى والمصابين & 0 \\
\hline$\% 9$ & 9 & العلامات الحيوية & 7 \\
\hline$\% 9$ & 9 & الإنعاش القلب رئوبي & $\mathrm{V}$ \\
\hline$\% 1$. & $1 \cdot$ & (إصابات الأنسجة الرخوة) والنزيف & $\Lambda$ \\
\hline$\% 1$. & 1. & طُق النقل الأمن للمصابين & 9 \\
\hline$\% 1$. & 1 . & طرق تركيب الممر الهوائي & $1 \cdot$ \\
\hline
\end{tabular}

يتضح من جدول (1) موافقة السادة الخبراء على كل المحاور المقترحة للبرنامج

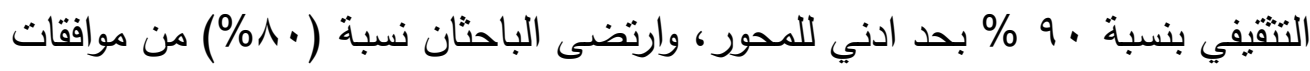
السادة الخبراء وبناء على هذا تم قبول جميع محاور البرنامج التنقيفي المقترح وعددهم لبنه

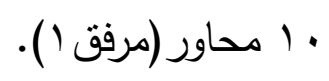




\section{تجميع المحتوي النظري للبرنامج التثقيفي المقترح:}

بعد أن وافق السـادة الخبراء علي كل محاور البرنامج التثقيفي المقترح والنقاط

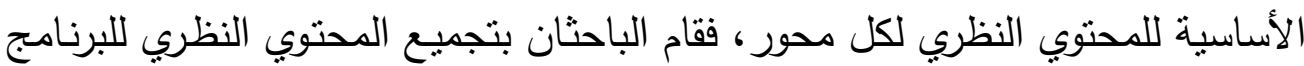

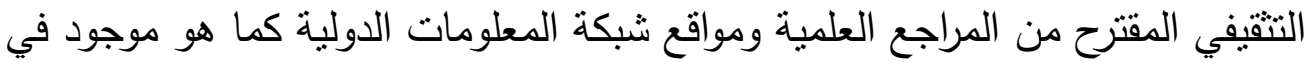

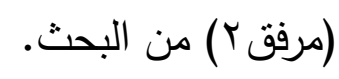

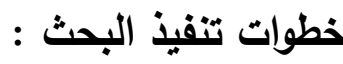

أولاً: إعداد محاور الاختبار المعرفي:

- تم عمل مسح للمراجع العلمية والدراسات السابقة ومواقع شبكة المعلومات الدولية لتحديد أهمية دراسة الإسعافات الأولية للعينة قيد البحث ثم تم تجميع ودمج هذهاته الأسباب لوضـعها في صسورة محساور رئيسية مقترحسة للاختبـار المعرفي وكـان عددهم عثـرة محاور (مرفق ب) وتم عرضـهم علي السـادة الخبراء وقد ارتضـي الباحثان نسبة (،^^\%) لقبول المحاور وتجاوزت نسبة الموافقة علي كل المحاور النسبة المحددة وتم قبول جميع المحاور • المبله ثانياً: إعداد عبارات الاختبار المعرفي: - لبناء الاختبار تم الاستعانة بالثلاث مستويات الأولي من الستة مستويات الرئيسية

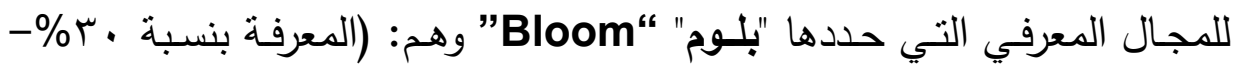
الفه بنسبة هץ\%- التطبيق بنسبة هץ\%)، ليكون عدد عبارات الاختبار المعرفي •

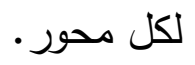
- تم كتابة فقرات الاختبار في صورته المبدئية (مرفق r) بنمط (ضع علامة صح

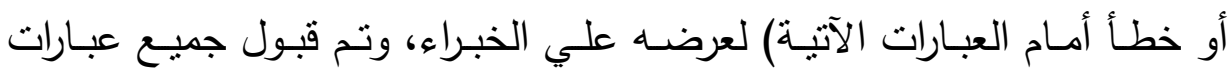
الاختبار المقترح.

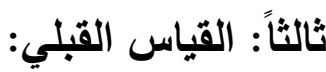
تطبيق الاختبار علي عينة لإجراء المعاملات العلمية : 


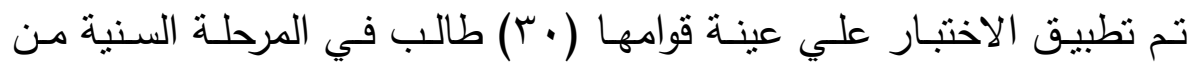

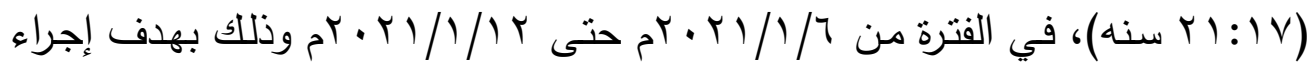

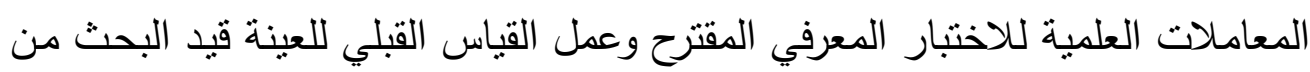
خلا تطبيق الاختبار المعرفي عليهم.

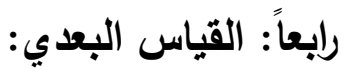

تم تطبيق الاختبار المعرفي بعد تطبيق البرنـامج التقيفي لمدة شـهر ونصف بواقع عشر محاضرات بواقع محاضرتين في الأسبوع وزمن كل وحدة ساعتين خلال

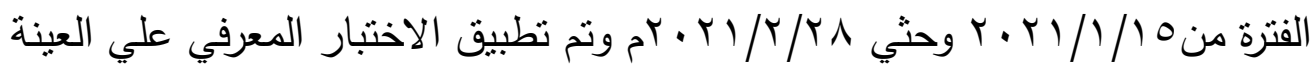

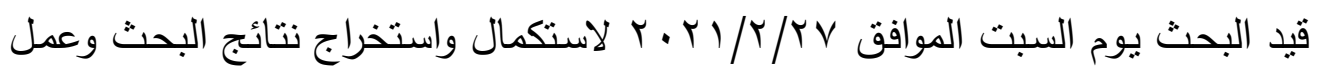
المعالجات الإحصائية اللازمة للبحث. لبن. المعالجات الإحصائية : الإنهات

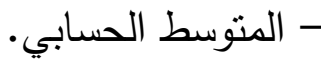

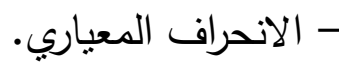
- معامل السهولة والصعوبة.

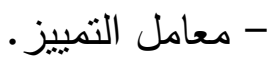

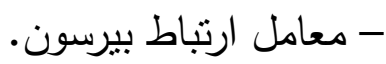

\section{جدول (r)}

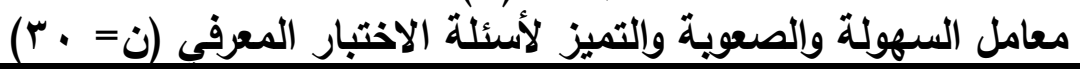

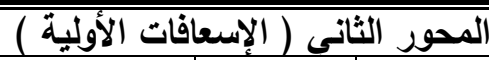

معامل الصعوية

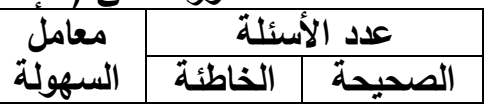

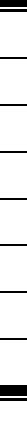

\begin{tabular}{|c|c|c|c|c|c|c|c|c|}
\hline معامل الصع & السهولة & الخاطئة & الصحيحة & & التمييز & الصعوية & السهولة & الخاطئة \\
\hline$\cdot . \varepsilon \wedge$ & $.0 \%$ & $1 \leqslant$ & 17 & $\overline{11}$ & 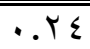 &. $.7 Y$ &.$r \Lambda$ & 11 \\
\hline $.0 Y$ &..$\leqslant \wedge$ & 10 & 10 & 2 &. Y. & $.0 Y$ &..$\leqslant \wedge$ & 10 \\
\hline .09 &..$\leqslant 1$ & IV & $1 \pi$ & 3 &..$Y \varepsilon$ &. .09 &..$\leqslant 1$ & IV \\
\hline. .09 &..$\leqslant 1$ & IV & $\pi$ & 4 &.$T \varepsilon$ &. .09 &..$\leqslant 1$ & IV \\
\hline .00 &..$\leqslant 0$ & 17 & $1 \varepsilon$ & 5 &. . YO & $\cdot . \leqslant \wedge$ &. $.0 Y$ & $1 \leq$ \\
\hline $.0 \%$ &..$\leqslant \Lambda$ & 10 & 10 & 6 & & & & \\
\hline .09 & ..51 & IV & $1 T$ & 7 & & & & \\
\hline .00 &..$\leqslant 0$ & 17 & $1 \leqslant$ & 8 & & & & \\
\hline
\end{tabular}




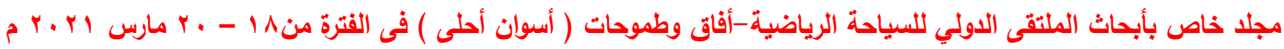

(العدد الرابع )

\begin{tabular}{l|c|c|c|c|c|c|c|c|c|c|c|}
\hline \hline$\Lambda$ & 1 & 9 & & & & \\
\hline
\end{tabular}

تابع جدول (r)

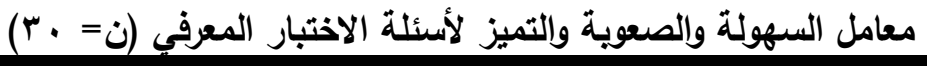

المحور الخامس ( الرعاية الأولية للمرضحى والمصابين ) ل المحور السادس ( العلامات الحيوية )

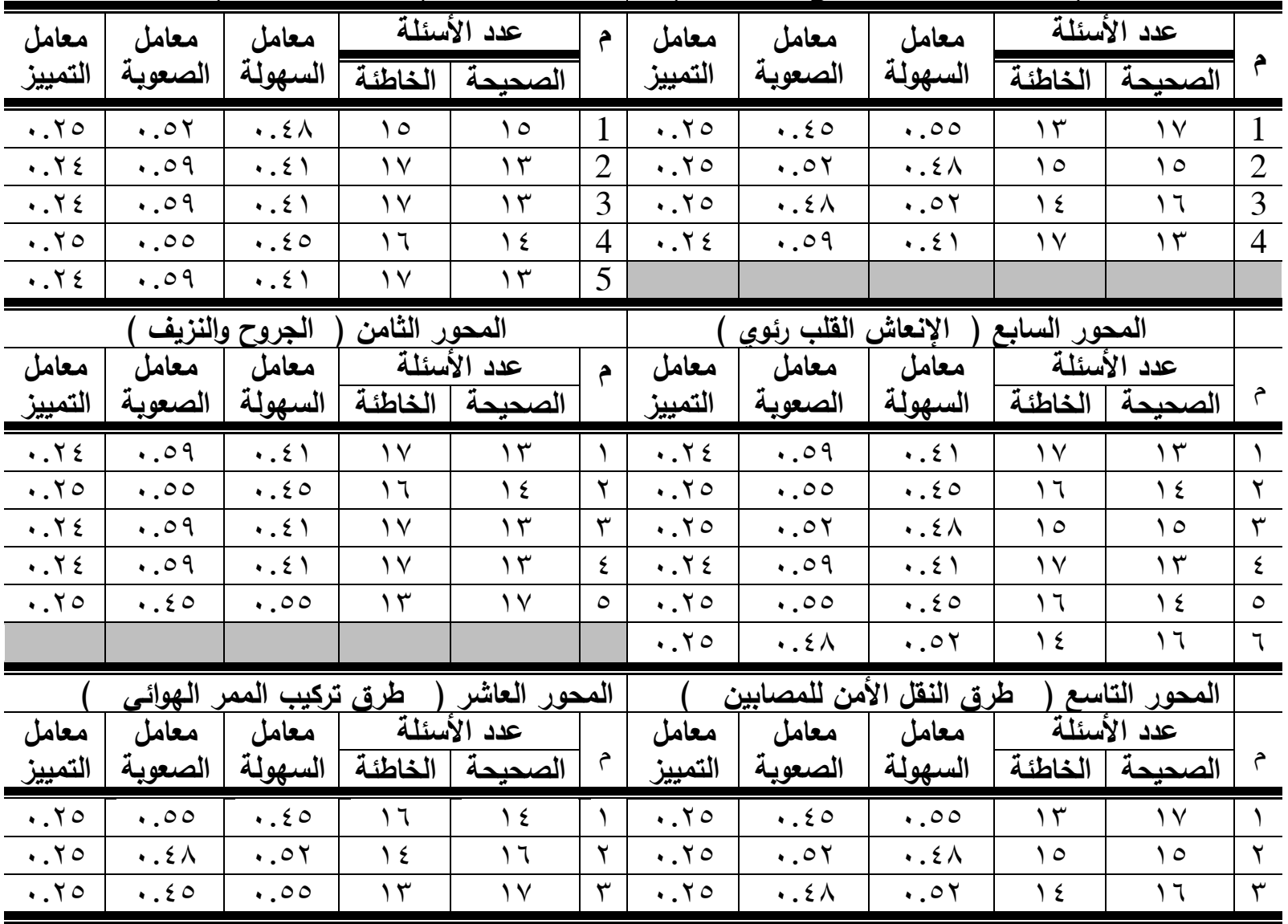




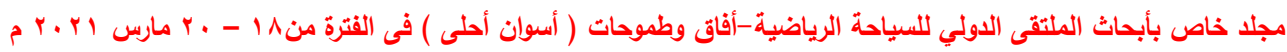

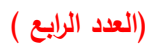

يتضح من جدول (Y) معامل السهولة ومعامل الصعوبة ومعامل التميز لأسئلة الاختبار المعرفي، كما يتضـح من الجدول أن جميع عبارات الاختبار المعرفي تتمتع بدرجة مقبولة في معامل السهولة ومعامل الصعوبة ومعامل التميز • 


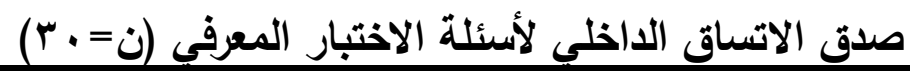

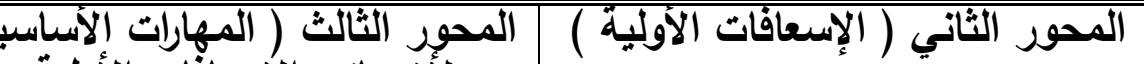
لأخصائي الإسعافات الأولية الأبية

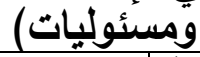

\begin{tabular}{|c|c|c|c|c|c|c|c|c|c|c|}
\hline الارتبا: & الالمعياري & المستابي & r & الارتباط & الانحرافي & المستوسطي & r & الارتباط & الانحعرافي & المستوسطى \\
\hline .385 & 0.504 & 1.567 & $\overline{1}$ & 0.642 & 0.504 & 1.567 & $\overline{11}$ & $\overline{0.431^{\prime \prime}}$ & 0.490 & 1.633 \\
\hline .585 & 0.498 & 1.600 & 2 & 0.642 & 0.504 & 1.567 & 2 & 0.793 & 0.498 & 1.600 \\
\hline .413 & 0.479 & 1.667 & 3 & 0.674 & 0.504 & 1.567 & 3 & 0.818 & 0.498 & 1.400 \\
\hline .433 & 0.498 & 1.400 & 4 & 0.683 & 0.490 & 1.367 & 4 & 0.651 & 0.466 & 1.300 \\
\hline & 1.979 & 6.234 & مج ( مج & 0.467 & 0.507 & 1.467 & 5 & 0.695 & 0.479 & 1.333 \\
\hline & & & & 0.831 & 0.479 & 1.667 & 6 & & 2.431 & 7.266 \\
\hline & & & & 0.725 & 0.507 & 1.467 & 7 & & & \\
\hline & & & & 0.457 & 0.509 & 1.500 & 8 & & & \\
\hline & & & & 0.585 & 0.498 & 1.600 & 9 & & & \\
\hline & & & & & 4.502 & 13.769 & مج & & & \\
\hline
\end{tabular}

المحور الخامس ( الرعايةٌ الأولية

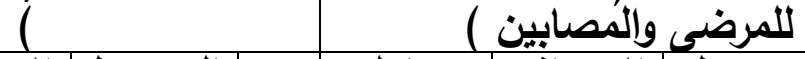

\begin{tabular}{|c|c|c|c|c|c|c|c|c|c|c|}
\hline الارتباة & الالنعرافي & الحستابي & r & الارتباطل & الالمعرافي & المستابيط & r & الارتباط & الانحعرافي & المستوسطى \\
\hline
\end{tabular}

\begin{tabular}{|l|l|l|l|l|}
\hline \hline .721 & 0.504 & 1.567 & 1 & \\
\hline .468 & 0.504 & 1.433 & 2 & \\
\hline .831 & 0.479 & 1.667 & 3 & \\
\hline .725 & 0.507 & 1.467 & 4 & \\
\hline .742 & 0.509 & 1.500 & 5 & \\
\hline & $\mathbf{2 . 5 0 3}$ & $\mathbf{7 . 6 3 4}$ & مجئl| &
\end{tabular}

\begin{tabular}{|c|c|c|c|c|c|c|}
\hline 0.367 & 0.507 & 1.533 & 1 & 0.454 & 0.490 & 1.633 \\
\hline 0.488 & 0.507 & 1.533 & 2 & 0.396 & 0.504 & 1.567 \\
\hline 0.479 & 0.509 & 1.500 & 3 & 0.742 & 0.509 & 1.500 \\
0.457 & 0.509 & 1.500 & 4 & 0.560 & 0.509 & 1.500 \\
& $\mathbf{2 . 0 3 2}$ & $\mathbf{6 . 0 6 6}$ & م 0.585 & 0.498 & 1.600 \\
& & & & 0.457 & 0.509 & 1.500 \\
& & & & & $\mathbf{3 . 0 1 9}$ & $\mathbf{9 . 3}$ \\
\hline
\end{tabular}

المحور التاسع ( طرق النقل

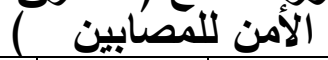

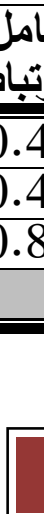

المحور الثامن ( الجروح والنزيف )

محور السابع ( الإنعاش القّلب رئوي )

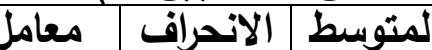

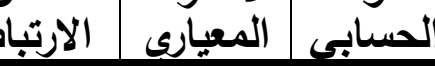

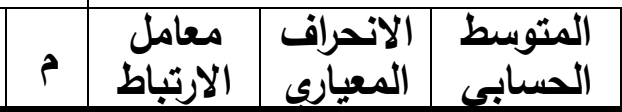

لمحور الأول (الخدمات الطبية العاجلة)

حور الرابع ( التقييم المبدئي للمصاب )

$0.490 \quad 1.633$

م

الارتباط

المتوسط | الانحراف

"0.467 0.507 1.467

0.635

المعياري

الحسابى

\begin{tabular}{|c|c|c|}
\hline 0.507 & 1.467 & 2 \\
\hline 0.479 & 1.667 & 3 \\
\hline 1.476 & 4.767 & $\pi$ \\
\hline
\end{tabular}

\begin{tabular}{ll|l|l|l}
0.831 & 0.479 & 1.667
\end{tabular}

20.836

0.466

1.700

0.7420 .509

1.500

0.367

0.450

1.733

\begin{tabular}{l|l|l|l|l}
0.560 & 0.509 & 1.500 & 4 & 0.488
\end{tabular}

0.507

1.533

$0.507 \quad 1.533$ 


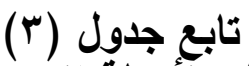

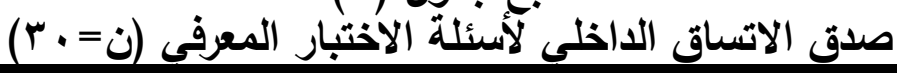

\begin{tabular}{|c|c|c|c|c|c|c|c|c|c|c|c|}
\hline (النقل & 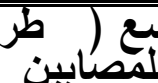 & محور الأمنان & & النزيف ) & ( الجروح & ور الثامن & المح & إئوي ) & شُ القًا & لـ السابع & \\
\hline معامل الارتباط & الالمعياريف & المتوبسط & e & الارتباط & الالمعيارى & الحستابسى & r & الارتباط & الإنحرافيارى & الحتوبسط & $r$ \\
\hline & & & & 0.721 & 0.504 & 1.567 & 5 & 0.742 & 0.509 & 1.500 & 5 \\
\hline & & & & & 2.5 & 7.7 & متج & 0.560 & 0.509 & 1.500 & 6 \\
\hline & & & & & & & & & 2.948 & 9.449 & מג \\
\hline & & & & الهوأئَ & تركيا & طرو & آلعائ & المحور & & & \\
\hline & & & & & & & & الارتباط & الالمعياري & سط الحستابح & e \\
\hline & & & & & & & & 0.722 & 0.466 & $\overline{1.300}$ & 1 \\
\hline & & & & & & & & 0.841 & 0.507 & 1.533 & 2 \\
\hline & & & & & & & & 0.776 & 0.430 & 1.767 & 3 \\
\hline & & & & & & & & & 1.4 & 4.6 & 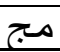 \\
\hline
\end{tabular}

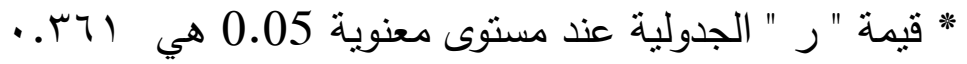

تشير نتائج الجدول رقم (3) إلى أنه توجد علاقة ارتباطيه داله إحصائياً بين

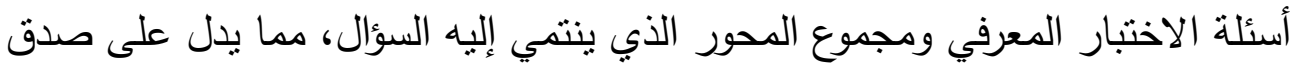

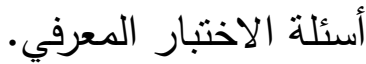

\section{جدول (4) (4)}

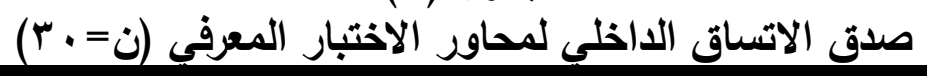

\begin{tabular}{|c|c|c|c|c|}
\hline 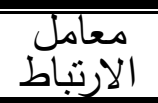 & الالانحرافي & الحستوسط & 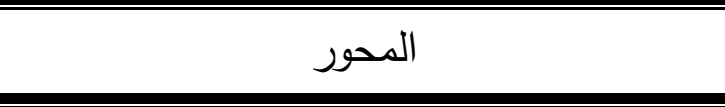 & 5 \\
\hline * 0.720 & 2.431 & 7.267 & مقدمة عن الخدمات الطبية العاجلة & \\
\hline$* 0.936$ & 4.502 & 13.769 & الإسعافات الاولية & 2 \\
\hline$* 0.617$ & 1.979 & 6.234 & المهارات الاساسية لاخصيائي الإسعافات الاولية & 3 \\
\hline .812 & 3.01 & 9.3 & التقبيم المبدئَي للمصاب & 4 \\
\hline .781 & 2.032 & 6.066 & الرعاية الاولية للمرضحي والمصابين & 5 \\
\hline *0.729 & 2.503 & 7.643 & العلآمات الحيوية & 6 \\
\hline$* 0.880$ & 2.948 & 9.449 & الإنعاش القلب رئوبي & 7 \\
\hline$* 0.757$ & 2.5 & 7.7 & (إصابات الأنسجة الرخوة) والنزيف & 8 \\
\hline$* 0.620$ & 1.467 & 4.767 & طرق النقل الامن للمصابين & 9 \\
\hline \multirow[t]{2}{*}{$* 0.629$} & 1.4 & 4.6 & طرق تركيب الممر الهوائي & \\
\hline & 24.772 & 76.704 & لاختبار & \\
\hline
\end{tabular}




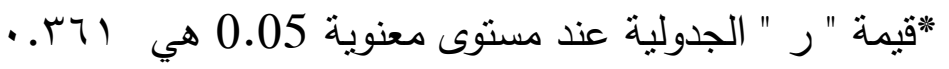
تشير نتائج الجدول رقم (4) إلى أنه نوجد علاقة ارتباطيه داله إحصائياً بين محاور الاختبار والمجموع الكلى للاختبار ، مما يدل على صدق محاور الاختبار المعرفي.

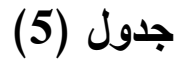

ثبات محاور الاختبار المعرفي بطريقة الاختبار واعادة تطبيقه (ن= ـ ب)

\begin{tabular}{|c|c|c|c|c|c|c|}
\hline \multirow{2}{*}{ 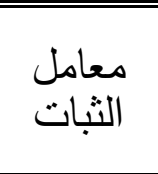 } & \multicolumn{2}{|c|}{ التطبيق الثاني } & \multicolumn{2}{|c|}{ التطبيق الأول } & \multirow[b]{2}{*}{ المحور } & \multirow[b]{2}{*}{ s } \\
\hline & الالمعراف & الحستابي & الالمعراف & الحستوسط & & \\
\hline$* 0.728$ & 2.501 & 7.311 & 2.431 & 7.267 & مقدمة عن الخدمات العاحلة & 1 \\
\hline$* 0.667$ & 4.69 & 13.88 & 4.502 & 13.769 & الإسعافات الأولية & 2 \\
\hline$* 0.559$ & 2.06 & 6.47 & 1.979 & 6.234 & 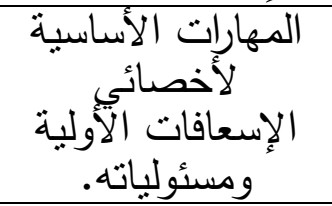 & 3 \\
\hline$* 0.436$ & 3.261 & 9.5 & 3.01 & 9.3 & التقيبم المبدئي & 4 \\
\hline$* 0.481$ & 2.134 & 6.23 & 2.032 & 6.066 & للمرضي والرعاية الأولية & 0 \\
\hline$* 0.532$ & 2.61 & 7.69 & 2.503 & 7.643 & العلامات الحيوية & 7 \\
\hline$* 0.587$ & 3.14 & 9.51 & 2.948 & 9.449 & الإنعاش القلب رئوبي & $\mathrm{V}$ \\
\hline$* 0.667$ & 2.61 & 7.92 & 2.5 & 7.7 & (إلصابات الأنسجة والنزبفت & $\wedge$ \\
\hline$* 0.667$ & 1.487 & 4.80 & 1.467 & 4.767 & طرق النقل الآمن & 9 \\
\hline$* 0.481$ & 1.48 & 4.71 & 1.4 & 4.6 & طرق تركيب الممر & 1 . \\
\hline${ }^{*} .921$ & 25.973 & 78.021 & 24.772 & 76.704 & مجموع الاختبار & \\
\hline
\end{tabular}

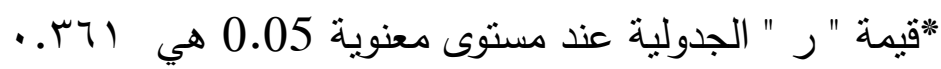
تشير نتائج الجدول رقم (5) إلى أنه توجد علاقة ارتباطيه داله إحصائياً بين محاور الاختبار والمجموع الكلى للاختبار ، مما يدل على ثلى لثبات المحاور والاختبار

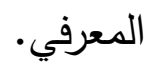




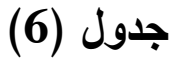

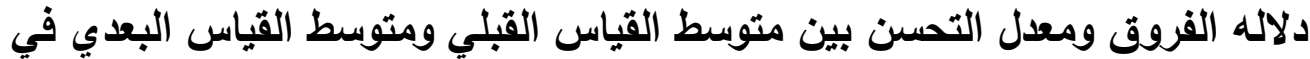

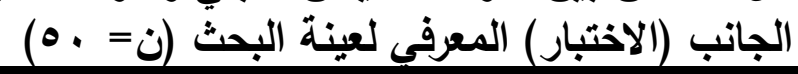

\begin{tabular}{|c|c|c|c|c|c|c|c|c|}
\hline \multirow[b]{2}{*}{ التحسبة } & \multirow[b]{2}{*}{ "تثمة } & \multirow[b]{2}{*}{ المنتّن } & \multicolumn{2}{|c|}{ القياس البعدي } & \multicolumn{2}{|c|}{ القياس القبلي } & \multirow[b]{2}{*}{ المحور } & \multirow[b]{2}{*}{ r } \\
\hline & & & الانتحرا & المشّدس & الانحرا & الحستّد & & \\
\hline $\begin{array}{c}36.5 \\
\%\end{array}$ & 7.51 & 2.653 & $\begin{array}{c}0.46 \\
4\end{array}$ & 9.92 & $\begin{array}{c}2.43 \\
1\end{array}$ & $\begin{array}{c}7.26 \\
7\end{array}$ & الخدامّات & 7 \\
\hline $\begin{array}{c}\% 28 \\
84\end{array}$ & 6 & 3.971 & 1.19 & $\begin{array}{c}17.7 \\
4\end{array}$ & 4.50 & $\begin{array}{c}13.7 \\
69\end{array}$ & الأتّعافا & $T$ \\
\hline$\underset{\%}{59.6}$ & $\begin{array}{c}12.9 \\
9\end{array}$ & 3.716 & $\begin{array}{c}0.32 \\
9\end{array}$ & 9.95 & $\begin{array}{c}1.97 \\
9\end{array}$ & $\begin{array}{c}6.23 \\
4\end{array}$ & 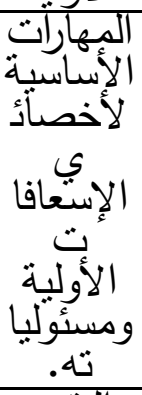 & $\Gamma$ \\
\hline $61_{\%}^{6.18}$ & 12.9 & 5.69 & $\begin{array}{c}0.61 \\
7\end{array}$ & $\begin{array}{c}14.9 \\
9\end{array}$ & 3.01 & 9.3 & & $\varepsilon$ \\
\hline $\begin{array}{c}30.2 \\
\%\end{array}$ & $\begin{array}{c}18.4 \\
1\end{array}$ & 5.764 & $\begin{array}{c}0.84 \\
1\end{array}$ & ${ }_{3}^{11.8}$ & $\begin{array}{c}2.03 \\
2\end{array}$ & $\begin{array}{c}6.06 \\
6\end{array}$ & لاللرالرضيّية & 0 \\
\hline $\begin{array}{c}94.68 \\
\%\end{array}$ & 19.5 & 7.237 & $\begin{array}{c}0.72 \\
8\end{array}$ & $\begin{array}{c}14.8 \\
8\end{array}$ & $\begin{array}{c}2.50 \\
3\end{array}$ & $\begin{array}{c}7.64 \\
3\end{array}$ & الحيوية & 7 \\
\hline $\begin{array}{c}47.21 \\
\%\end{array}$ & 10.3 & 4.461 & $\begin{array}{c}0.49 \\
4\end{array}$ & 13.9 & 2.94 & $\begin{array}{c}9.44 \\
9\end{array}$ & الألقنباش & V \\
\hline $\begin{array}{c}\% \\
65.45\end{array}$ & $\begin{array}{c}12.7 \\
9\end{array}$ & 5.04 & $\begin{array}{c}1.19 \\
4\end{array}$ & $\begin{array}{c}12.7 \\
4\end{array}$ & 2.5 & 7.7 & الألأنسابَّة & $\wedge$ \\
\hline 107.4 & 23.7 & 5.123 & 0.41 & 9.89 & 1.46 & 4.76 & طرق & 9 \\
\hline
\end{tabular}




\begin{tabular}{|c|c|c|c|c|c|c|c|c|}
\hline$\%$ & 1 & & 7 & & 7 & 7 & النيقل & \\
\hline $\begin{array}{c}93.69 \\
\%\end{array}$ & $\begin{array}{c}20.6 \\
2\end{array}$ & 4.31 & $\frac{0.48}{5}$ & 8.91 & 1.4 & 4.6 & & 1 \\
\hline $91_{\%} .18$ & $\begin{array}{c}24.8 \\
5\end{array}$ & 69.94 & $\begin{array}{c}6.76 \\
3\end{array}$ & 124. & $\begin{array}{c}24.7 \\
72\end{array}$ & $\begin{array}{c}76.7 \\
04\end{array}$ & & \\
\hline
\end{tabular}

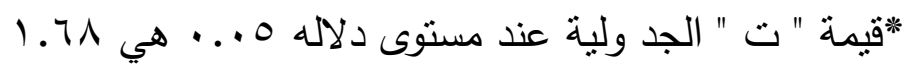

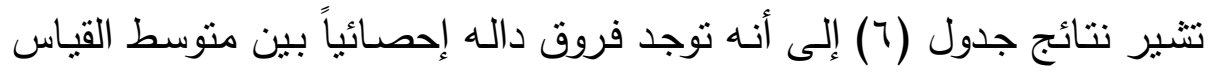

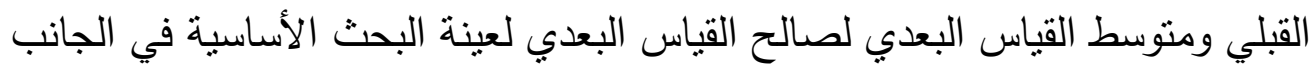

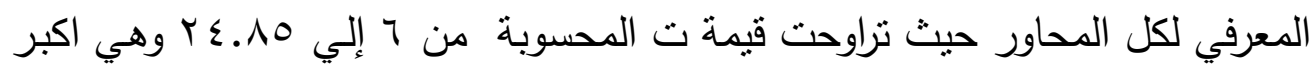

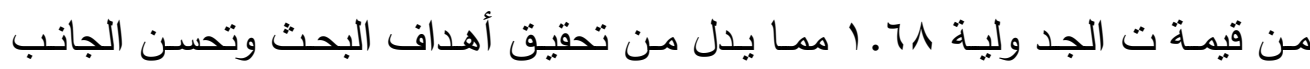

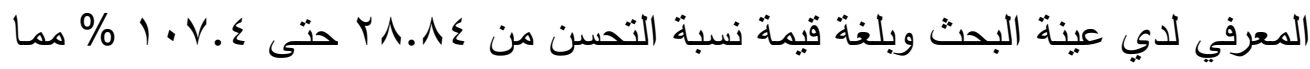
يدل على تحسن عينة البحث في جميع محاور البحث ومجموع الاختبار للى عينة البحث.

\section{الاستتتاجات :}

\section{في ضوء هدف البحث ومن خـلال مـا تم من إجراءات ومعالجات إحصائية}

$$
\text { توصل الباحث إلي: }
$$

ا- بناء اختبار معرفي لقياس المستوي المعرفي للفرق الرياضية بمحافظة اسوان عن أهمية الإسعافات الأولية.

r- انخفاض المستوي المعرفي لدي طلاب الفرق الرياضية بمحافظة اسوان عن أهمية الإسعافات الأولية بسيناء.

ب- تصـميم برنـامج تثقيفي للوقايـة عن أهميـة الإنسعافات الأوليـة الفـرق الرياضـية

$$
\text { بمحافظة اسوان. }
$$

ع- البرنامج التثقيفي أظهر تحسن واضح في المستوى المعرفي لدي عينة البحث عن البن

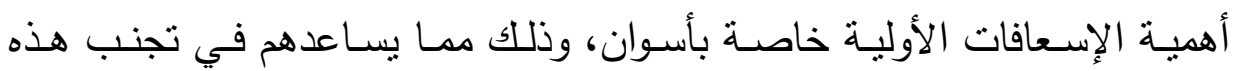

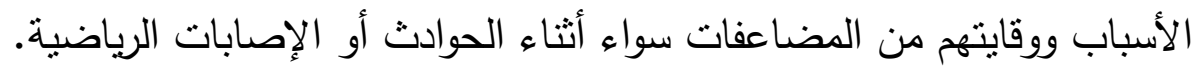


0- البرنـامج التثقيفي أظهر تحسن واضـح في المستوى المعرفي لدي عينـة البحث

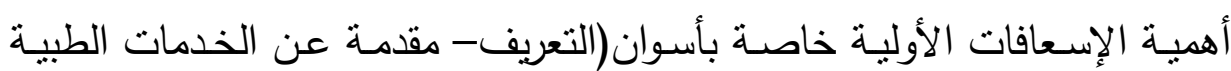

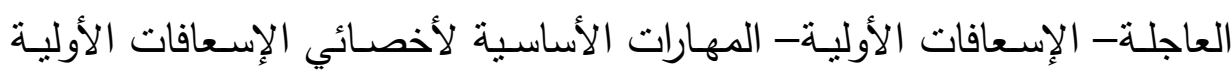

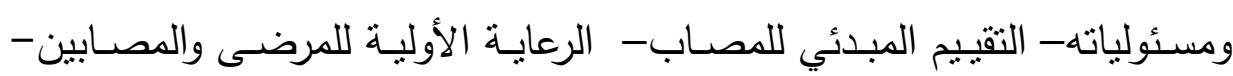

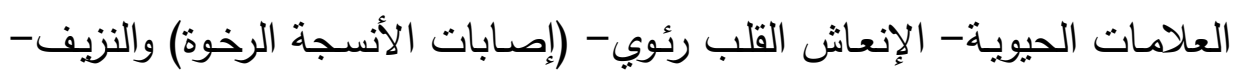

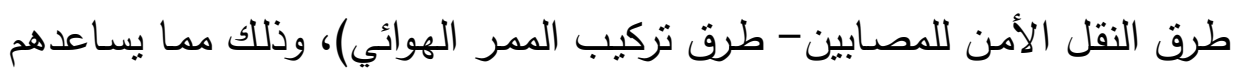

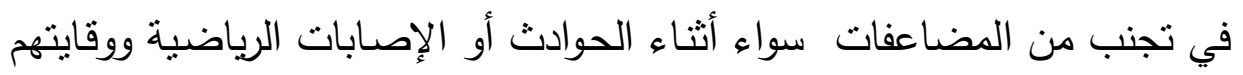
من الوقوع فيها عن قصد أو غير قصد. أوفاع.

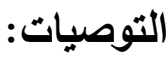

في ضوء ما توصل إليه الباحث من استنتاجات وذلك من خـلال مـا تم من

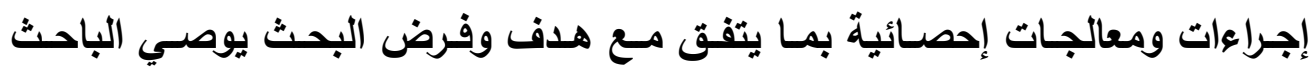
بالاتي: 1- الاستعانة بالاختبار المعرفي وتطبيقه علي الفرق الرياضية بمحافظة اسوان في

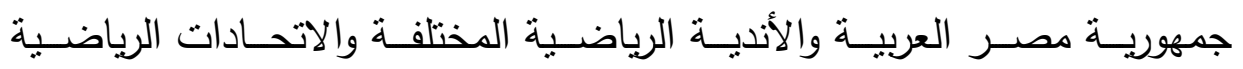

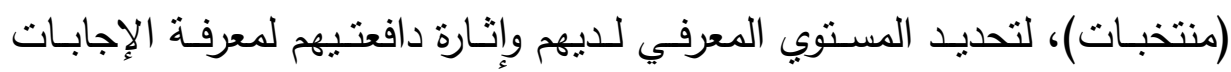
الصحيحة.

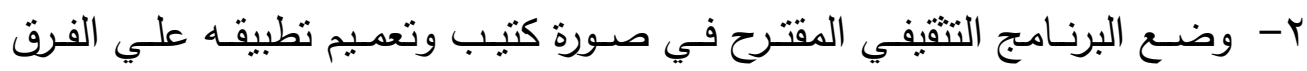

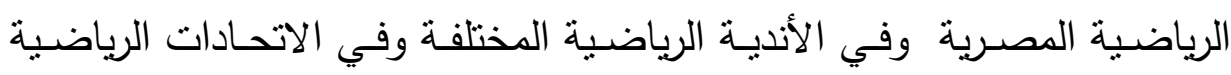

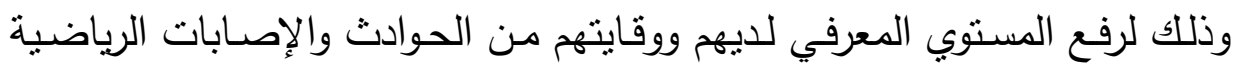
بالتعاون مع هيئة الإسعاف المصرية.

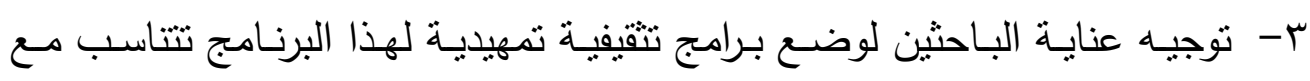

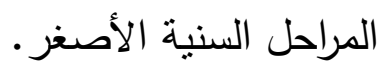
ع- توجيـه عنايـة البـاحثن لوضـع بـرامج تلقيفيـة تكميليـة (متقدمـة) للمراحل السـنية

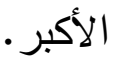


0- توجيـه عنايـة البـاحثين في الأقسـام الأخرى (قسم علم النفس الرياضـي) لوضـع

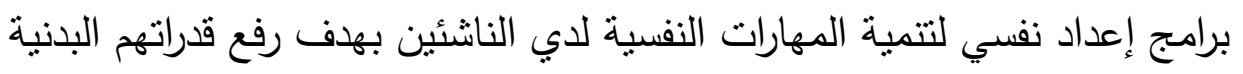

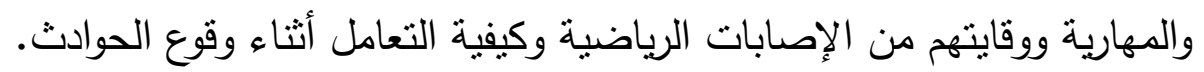

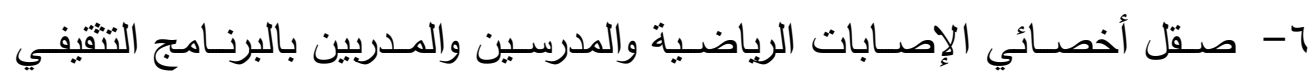

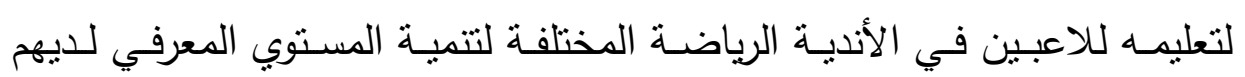
ووقايتهم من الإصابات الرياضية. - اقتراح مقرر دراسي لطلاب كليات التربية البدنية والرياضة" الإسعافات الأولية بين الإباته النظرية والتطبيق وصقلهم به خلا السنوات الدراسية الأربعة مع التنسيق مع هيئة

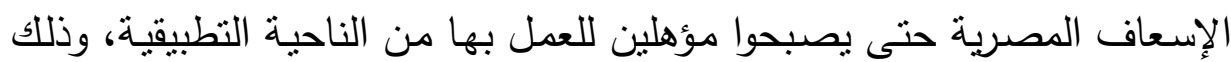

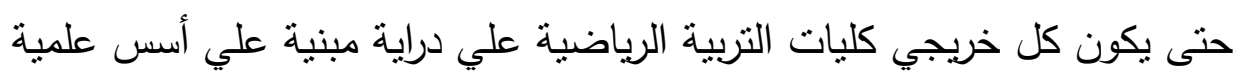

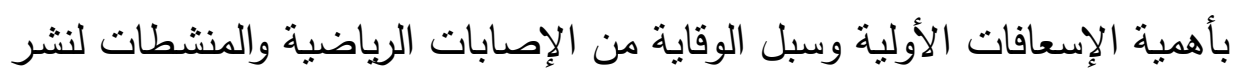
هذه الثقافة في الأوساط الرياضية والمدرسية. 1- وضع برامج تثقيفية رياضية صحية مشـابهه لطلاب المدارس في جميع المراحل السنية. 


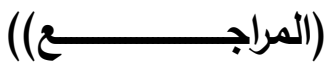

أولاً: المراجع العربية

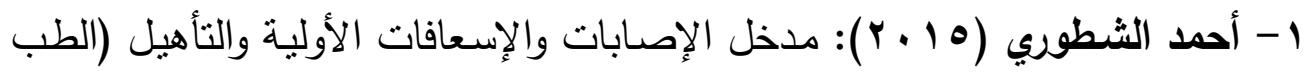

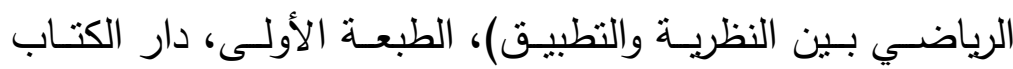

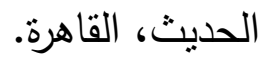

r- أمين الخولي ومحمود عنان (99 9 (1م): المعرفة الرياضية، الطبعة الأولي، دار الفكر العربي، القاهرة.

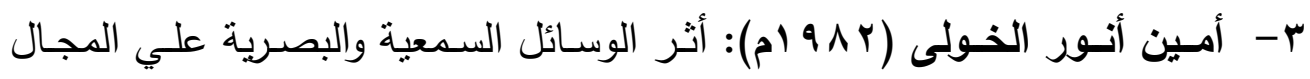

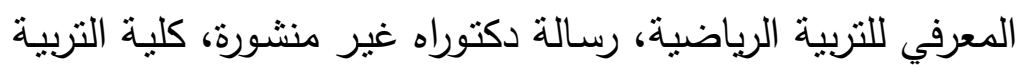

الرياضية للبنين، القاهرة.

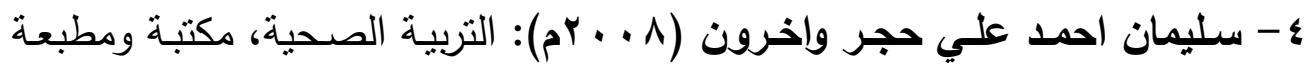

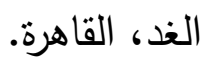

ه- عبد الرحمن عبد الحميد زاهر(1 +. ب): موسوعة الإصابات الرياضية وإسعافاتها

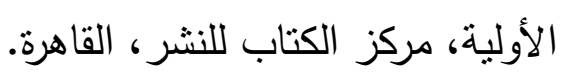

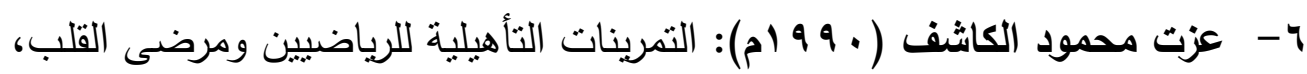
مكتبة النهضة المصرية.

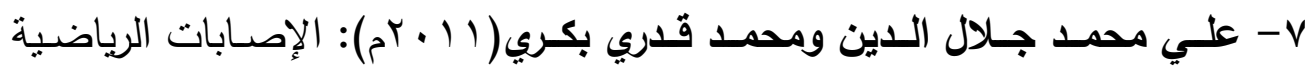

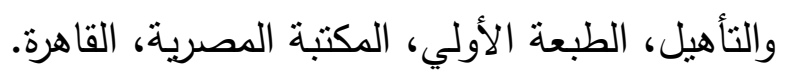

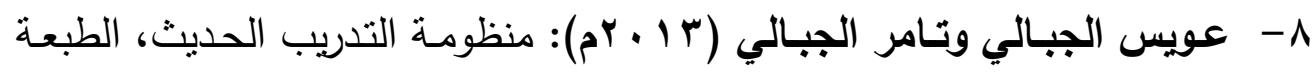
الثانية، دار ابو المجد للطباعة بالهرم، القاهرة.

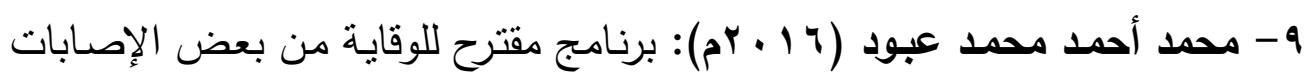

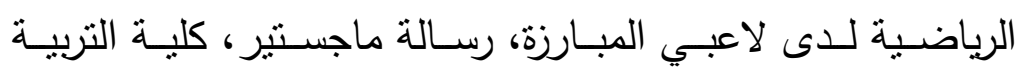

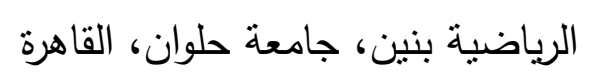

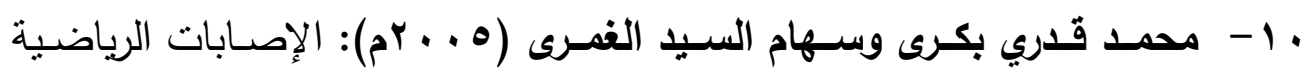
والتأهيل البدني، دار المنار للطباعة، القاهرة. 


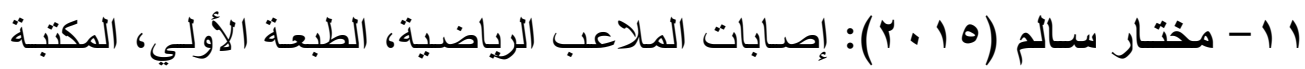
المصرية، القاهرة.

r ا - مهـا حنفي قطب محمــ وآخـرون (9 . . . rم): الإصـابات الرياضية والعـلاج الحركي، دار الإسراء للطباعة، القاهرة.

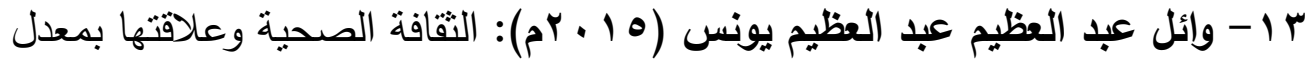
الإصـابات لدى ناشئي ألعاب القوى، رسالة ماجستير ، كلية التربية الرياضية بنين، جامعة حلوان، القاهرة.

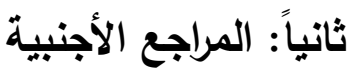

14- Charles, A Bucher and Evelyn M. Read (1971) : Physical Education and Health in the Elementary school, New York, U.S.A.

15- Donald, K. Mathews D. P. (1978) : "Measurements in Physical Education" W.B. Saunders, Company, Philadelphia, London, Toronto.

16- Helen, M.Eckert (1974) : "Practical Measurement of Physical Performance", London.

17- Singer, Robert N \& dick, Walter (1980) : Teaching physical education, A systems approach, Second ed, Houghton Mifflin co. Boston.

18- Taba, H (1975): "Curriculum Development Theory and Practice" New York, Harcourt, Brece Jovonavich.

19- Williams, Frank E (1969) : Models for encouraging creativity in the class room by integrity Cognitive effective behaviors, educational technology, December. 